\title{
Air Templated Macroporous Epoxy Foams with Silica Particles as Property-Defining Additive
}

\author{
Mohammad Jalalian, Qixiang Jiang, ${ }^{*}$ and Alexander Bismarck*(1) \\ Institute of Material Chemistry and Research, Polymer \& Composite Engineering (PaCE) Group, Faculty of Chemistry, University \\ of Vienna, Währinger Strasse 42, 1090 Vienna, Austria
}

\section{Supporting Information}

\begin{abstract}
Nonaqueous foams were successfully produced by mechanically beating air into liquid epoxy resin, surfactant, and silica particle mixtures and used as templates to produce macroporous polymers. The air bubbles introduced into the epoxy formulations served as templates for the pores of the cured epoxy foams. The addition of silica particles into the resin mixture resulted in an increased viscosity of the formulation, thus enhancing the stability of the liquid epoxy froths, which could then be thermally cured at $60^{\circ} \mathrm{C}$. Increasing the silica loading in the formulation resulted in an increase of the foam density and decrease of the average pore size of the epoxy foams. The epoxy foams containing silica exhibited a hierarchical pore structure, where large pores were surrounded by smaller pores, and enhanced stiffness as compared to the control epoxy foams with a monomodal pore size distribution.
\end{abstract}

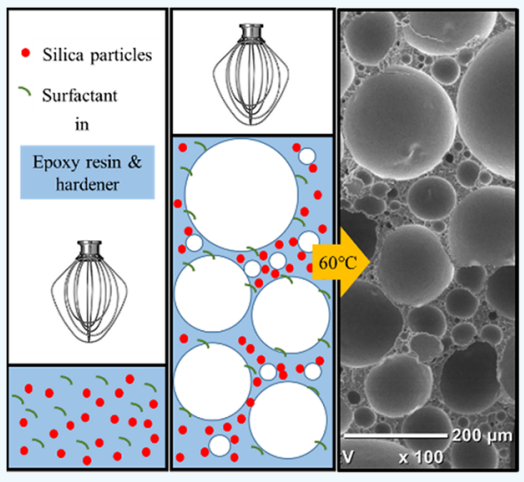

KEYWORDS: epoxy foam, nonaqueous foams, frothing, hierarchical porous structure, templating

\section{INTRODUCTION}

Epoxy foams exhibit excellent properties, including low shrinkage, low moisture uptake, ${ }^{1}$ good thermal and chemical stability, as well as mechanical properties even at low foam density. ${ }^{2}$ These properties have resulted in many applications of epoxy foams in structural materials, such as sandwich composites, ${ }^{3}$ in construction and the automotive industry. ${ }^{1}$

Epoxy foams are produced using various methods. Physical blowing agents, such as hexane or cyclohexane, can be mixed into epoxy resin and hardener formulations. ${ }^{4}$ During the exothermic curing reaction between resin and hardener, the physical blowing agents expand and foam the still liquid but curing epoxy formulations. Chemical blowing agents have been widely used to foam epoxy resins both in research ${ }^{1,5,6}$ and production of commercial epoxy foams, such as for instance the PB series epoxy foams (Sicomin, France). ${ }^{7}$ Chemical blowing agents react with components in the epoxy resin, usually the amino hardener, ${ }^{1,5}$ and generate gas to expand the resin/hardener mixture. Syntactic epoxy foams have been produced by mixing the resin and hardener with hollow (or expanding) spheres followed by curing of the resin. ${ }^{2,8,9}$ Syntactic epoxy foams have a controllable density, but their density is usually higher compared to that of epoxy foams produced by either chemical or physical blowing. ${ }^{10}$ Epoxy foams produced by emulsion templating were also reported. ${ }^{11,12}$ Emulsions whose continuous but minority phase consisted of a mixture of epoxy resin/hardener and an internal aqueous templating phase have been produced; curing of the resin phase and the subsequent removal of the internal aqueous phase led to macroporous epoxies, whose density and pore size can be controlled by tuning the emulsion phase volume ratio and the droplet size of the emulsions, respectively.

Air templating is an alternative method to produce polymer foams from nonaqueous foam precursors. Air is mechanically whipped or beaten into liquid monomers or resins, ${ }^{13-15}$ and the introduced air forms spherical bubbles which are kinetically stable if the liquid viscosity is high enough. The polymerization/curing of the monomers or resins results in macroporous polymer foams, where the pores are templated by air bubbles. One advantage of air templating as compared to the conventional blowing or syntactic methods is that no costly porogens are needed. Furthermore, nonaqueous foam templating does not require the removal, i.e. by drying, of any liquid templating phase from the resulting polymer foams, making it superior to emulsion templating. Contrary to nonaqueous foams, aqueous foam templates are much easier to be stabilized ${ }^{16}$ and were used as templates for the fabrication of various porous materials. ${ }^{17,18}$ Porous polymers were made from aqueous liquid foams consisting of a continuous aqueous solution of poly(vinyl alcohol) and formaldehyde; ${ }^{19}$ the foam was subsequently cured to produce open-porous hydrogels. Aqueous tannin solutions were mechanically frothed and cured to produce macroporous tannin, which was subsequently pyrolyzed to produce carbon foams. ${ }^{15}$ Black liquors, a byproduce from Kraft-mill, ${ }^{20}$ have also been mechanically

Received: November 8, 2018

Accepted: January 28, 2019

Published: January 28, 2019 
whipped into froths, and the lignin was cured to produce macroporous materials; these materials were also used as precursors for the production of carbon foams by pyrolysis. Schueler et al. ${ }^{21}$ introduced foamed (styrene-in-water) emulsion templates; the polymerization of the styrene droplets dispersed in the continuous aqueous phase resulted in macroporous polystyrene.

Air templated epoxy foams were disclosed earlier in a patent by Simpson et al. ${ }^{22}$ In the disclosed example, nitrogen gas was injected and whipped into a mixture of epoxy resin, hardener, and surfactant. After molding and curing of the liquid epoxy froths, epoxy foams with a foam density in the range of $288 \mathrm{~kg} /$ $\mathrm{m}^{3}$ to $689 \mathrm{~kg} / \mathrm{m}^{3}$ were produced. Lau et al. ${ }^{23}$ reported mechanical whipping of air using a kitchen blender into a liquid epoxy resin/hardener mixture, resulting in liquid epoxy froths; subsequent curing of the froths produced macroporous epoxy resins. The authors claimed that the viscous nature of the resin reduced the drainage of liquid resin from the films separating the entrapped bubbles in the epoxy froths, thus preventing froths from collapsing; a highly viscous epoxy/ hardener mixture without surfactant was therefore used. More recent work by Song et al. ${ }^{24}$ demonstrated the possibility to control the pore size of the epoxy foams by controlling the curing temperature of the liquid froth templates. Increasing the curing temperature of the epoxy resin caused thermal expansion of the entrapped air bubbles in the froth, which simultaneously resulted in a further decrease of the foam density. ${ }^{24}$ However, it was necessary to precure all liquid epoxy froth templates at room temperature, which is not a time efficient method to produce epoxy foams.

Many types of additives have been added to conventional epoxy foams to tailor the properties of the resulting foams. Carbon nanotubes were added to epoxy foams to enhance their electrical conductivity. ${ }^{9}$ Because a foam structure consists of mainly high aspect ratio polymer walls, the percolation threshold of the carbon nanotubes in polymer phase of the epoxy foam was reduced; therefore, a low nanotube loading resulted already in percolation of the nanotubes and thus boosted the electrical conductivity of the solid foam. Rice husk ash has been used in a chemical blowing process for the production of foamed epoxy composites. ${ }^{25}$ The addition of the rice husk ash, due to its nucleation effect, resulted in a reduced average pore size of the epoxy foams. Furthermore, white rice husk ash has been found to result in improved mechanical properties of the epoxy foams. Silica particles have also been found to enable the nucleation of gas bubbles during conventional blowing processes; they contributed to small pore sizes in the resulting epoxy foams or, when the silica loading exceeded a certain weight fraction, led to epoxy foams with a bimodal pore size distribution. ${ }^{10}$ Furthermore, the presence of silica particles in the cured epoxy resin resulted in an increased glass transition temperature of the epoxy.

Here, we describe a method to produce epoxy foams using the nonaqueous foam templating method. The addition of silica particles to liquid resin formulations was shown to increase the viscosity of epoxy resin formulations, ${ }^{26}$ which was hypothesized to be the key in stabilizing liquid epoxy froths. ${ }^{23}$ Using silica particles to tune the morphology of blown epoxy foams has been reported. We aimed to produce low density epoxy foams with a fine cell structure using silica particles as property-defining additives in a commercial liquid epoxy formulation. We also anticipate that the incorporated silica particles will act as reinforcement ${ }^{27,28}$ and thermal stabilizers ${ }^{29}$ of epoxy foams.

\section{EXPERIMENTAL DETAILS}

2.1. Materials. Epoxy L (EPL) and hardener GL1, purchased from R\&G Faserverbundwerkstoffe GmbH (Waldenbuch, Germany), were used as matrix, and poly(ethylene glycol)-block-poly(propylene glycol)-block-poly(ethylene glycol) (Pluronic L-81) (Sigma-Aldrich) was used as surfactant. Pyrogenic silica particles HDK H18 were kindly supplied by Wacker Co. (Germany). The fumed silica particles have a primary particle size of about $5-30 \mathrm{~nm}$ as determined by scanning electronic microscopy. ${ }^{30}$ The size of the fumed silica particles was determined by measuring the particles in tetrahydrofuran by dynamic light scattering (DLS, Malvern Zetasizer Nano ZS, Malvern, UK). The particle size was $120 \mu \mathrm{m}$ with a polydispersity index of 0.16. All chemicals were used as received.

2.2. Preparation of Epoxy Foam. EPL, GL1, and Pluronic L-81 were mixed with or without silica particles in $50 \mathrm{~mL}$ of free-standing polypropylene centrifuge tubes using a $450 \mathrm{~W}$ hand mixer equipped with a dough kneading head (Figure S1). The mixing also simultaneously introduced air into the mixture by mechanical whipping. The produced epoxy froths were subsequently cured either at room temperature or in an oven at the desired curing temperatures for $24 \mathrm{~h}$ (following the suggested curing protocol of the manufacturer). The formulations, frothing time, and curing conditions are summarized in Table 1. In general a "foam" can be both liquid and solid; in this paper, the solid macroporous epoxy resin is called epoxy foam, while the liquid precursor is called epoxy froth.

Table 1. Resin Formulation, Frothing Time, and Curing Temperature of Epoxy Froths

\begin{tabular}{lcccccc} 
& $\begin{array}{c}\mathrm{EPL} \\
(\mathrm{vol} \\
\%)^{a}\end{array}$ & $\begin{array}{c}\mathrm{GL1} \\
(\mathrm{vol} \\
\%)^{a}\end{array}$ & $\begin{array}{c}\mathrm{L}-81 \\
(\mathrm{vol})\end{array}$ & $\begin{array}{c}\mathrm{SiO}_{2} \\
(\mathrm{w} / \mathrm{v} \\
\%)^{b}\end{array}$ & $\begin{array}{c}\text { frothing } \\
\text { time } \\
(\mathrm{min})\end{array}$ & $\begin{array}{c}\text { curing } \\
\text { temperature } \\
\left({ }^{\circ} \mathrm{C}\right)\end{array}$ \\
\hline 1A & 68 & 20 & 12 & 0 & 12 & 21 \\
1B & 68 & 20 & 12 & 0 & 12 & 60 \\
2A & 68 & 20 & 12 & 0.2 & 12 & 60 \\
2B & 68 & 20 & 12 & 0.5 & 12 & 60 \\
2C & 68 & 20 & 12 & 1 & 12 & 60 \\
2D & 68 & 20 & 12 & 2 & 12 & 60 \\
2E & 68 & 20 & 12 & 2.5 & 12 & 60 \\
2F & 68 & 20 & 12 & 5 & 12 & 60 \\
2G & 68 & 20 & 12 & 10 & 12 & 60 \\
3A & 68 & 20 & 12 & 2.5 & 2 & 60 \\
3B & 68 & 20 & 12 & 2.5 & 6 & 60 \\
3C & 68 & 20 & 12 & 2.5 & 24 & 60 \\
4A & 68 & 20 & 12 & 2.5 & 12 & 80 \\
4B & 68 & 20 & 12 & 2.5 & 12 & 100
\end{tabular}

${ }^{a}$ Volume ratio of the liquid components is expressed with respect to the total volume of the liquid phase. ${ }^{b}$ Silica particle loading with respect to the liquid phase volume.

2.3. Characterization of Liquid Epoxy Froths and Solid Epoxy Foams. The viscosity $\eta$ of the liquid mixture of epoxy resin, hardener, surfactant, and silica particles was determined using a rotational rheometer (Discovery Hybrid Rheometer RH2, TA Instruments, Germany). The liquid epoxy resin, hardener, surfactant, and silica particles were mixed in a centrifuge tube until the silica particles were dispersed. A stainless-steel geometry with cone angle of $1^{\circ}$ and $40 \mathrm{~mm}$ diameter was used. The viscosity of the resin mixture was measured as a function of shear rate in the range from 0.01 to 100 $\mathrm{s}^{-1}$ at $25{ }^{\circ} \mathrm{C}$

To investigate morphology of the epoxy foams, the epoxy foams were hand-broken; small pieces of fragments were fixed on carbon stickers. The fracture surface of the epoxy foams was gold-coated for $40 \mathrm{~s}$ at $30 \mathrm{~mA}$ in a sputter coater (JEOL Fine Coater JFC-1200, 

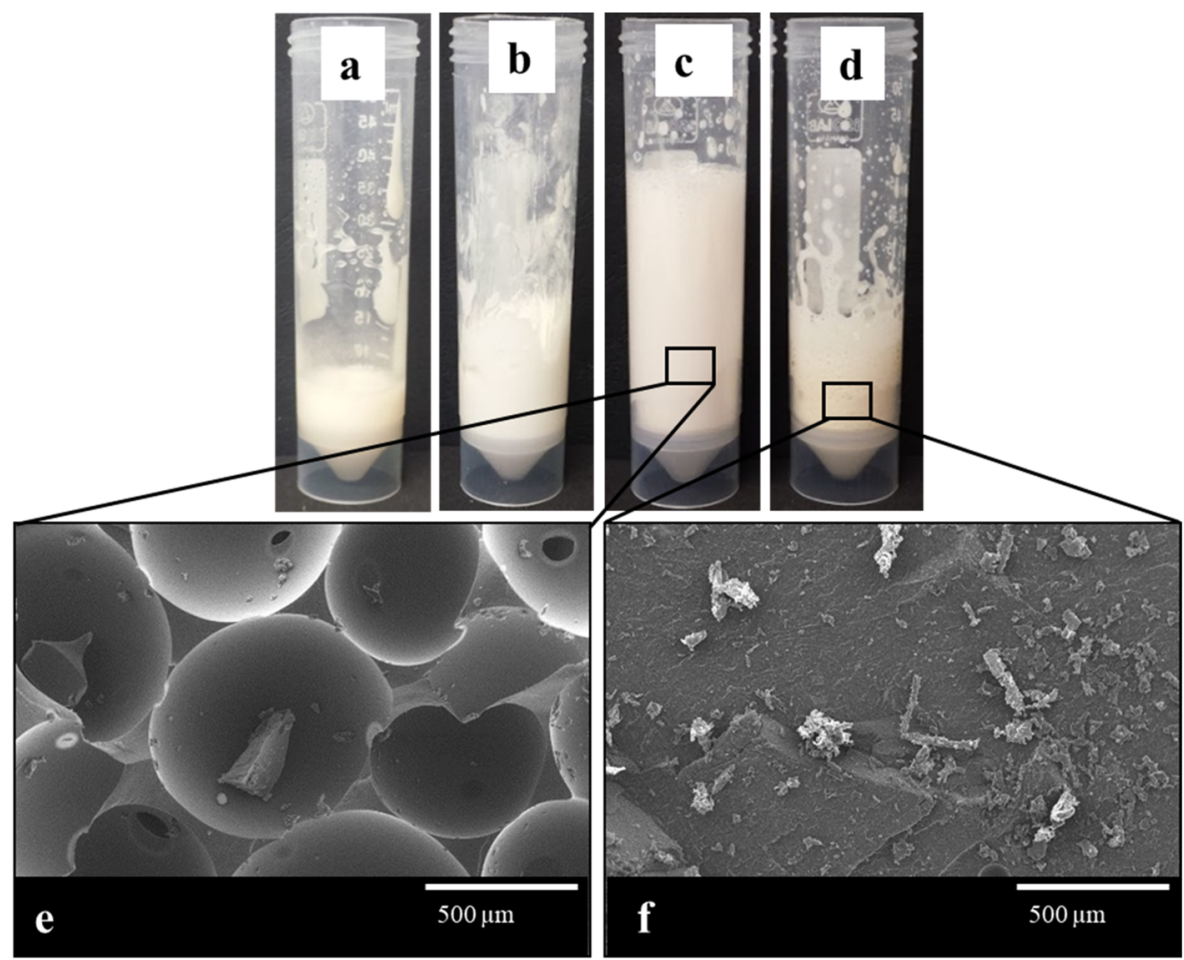

Figure 1. Preliminary formulation trials: (A) epoxy resin/hardener; (B) epoxy resin/hardener/silica particles; (C) epoxy resin/hardener/surfactant, cured at $23{ }^{\circ} \mathrm{C}$; (D) epoxy resin/hardener/surfactant, cured at $60^{\circ} \mathrm{C}$. Curing the epoxy froth at room temperature resulted in epoxy foams with a semiopen porous structure (e), while curing the identical epoxy froths at $60^{\circ} \mathrm{C}$ led to nonporous epoxy polymers (f).

Germany). SEM was carried out in the secondary electron beam mode using an electron acceleration voltage of $15 \mathrm{kV}$. Image J was used to analyze the SEM images of the epoxy foams; to obtain an average pore size with statistical significance, at least 150 pores were measured.

The foam density $\rho_{\mathrm{f}}$ of solid epoxy foams was quantified on cut samples, whose diameter $d$ and height $h$ were measured. The foam densities were calculated:

$$
\rho_{\mathrm{f}}=\frac{m}{V}=\frac{4 m}{\pi d^{2} h}
$$

where $m$ is the mass of the epoxy foam sample. To measure the skeletal density $\rho_{\mathrm{s}}$ of the cured epoxy foam, about $0.5 \mathrm{~g}$ of ground powder of epoxy foams was subjected to helium displacement pycnometry (AccuPyc II 1350, Micrometrics Aachen, Germany). The porosity $P$ of the epoxy foams was calculated:

$$
P=\left(1-\frac{\rho_{\mathrm{f}}}{\rho_{\mathrm{s}}}\right) 100 \%
$$

A universal mechanical tester (Model 5969, Instron $\mathrm{GmbH}$, Buckinghamshire, UK) was used to perform compression tests on epoxy foams. A $50 \mathrm{kN}$ load cell was attached to the mechanical tester. The test method was adapted from standard BS ISO 844. Test specimens with a diameter of $25 \mathrm{~mm}$ and a height of $10 \mathrm{~mm}$ were placed between two Teflon coated flat compression plates. The test speed was $1 \mathrm{~mm} \mathrm{~min}{ }^{-1}$. The epoxy foams were compressed by $30 \%$ while recording stress-strain curves. The elastic moduli $E$ of the epoxy foams were determined from the slope of the first linear region of the stress-strain curves; the crush strength $\sigma$ of the epoxy foams was the strength at the end of the first linear region. A minimum of at least five specimens of each sample was tested to obtain elastic moduli and crush strengths with statistical significance.

The curing kinetics of the epoxy formulation was investigated by differential scanning calorimetry (DSC, Discovery DSC, TA Instrument, Germany). Ten milligrams of mixtures of epoxy resin, hardener, and surfactant with or without silica particles were heated to $60{ }^{\circ} \mathrm{C}$ at a heating rate of $20^{\circ} \mathrm{C} / \mathrm{min}$ and isothermal for $3 \mathrm{~h}$. The heat flow curves were plotted as a function of time. Glass transition temperatures $\left(T_{\mathrm{g}}\right)$ of the cured epoxy foams were also determined by DSC. Ten milligrams of epoxy foam powder was heated/cooled/ heated/cooled between 20 and $150{ }^{\circ} \mathrm{C}$ at a ramping rate of $10{ }^{\circ} \mathrm{C} /$ min. The heat flow curves were plotted as a function of temperature.

Dynamic mechanical thermoanalysis (DMTA) was performed using a RSA-G2 (TA Instruments, United States) to determine glass transition temperatures $T_{\mathrm{g}}$ of the epoxy foams. Rectangular shaped specimens with dimensions of $10 \times 10 \times 5 \mathrm{~mm}$ were prepared and tested in compression mode at a frequency of $1.0 \mathrm{~Hz}$ from 30 to 150 ${ }^{\circ} \mathrm{C}$ at a heating rate of $2{ }^{\circ} \mathrm{C} / \mathrm{min}$ and an oscillation amplitude of $0.1 \%$.

\section{RESULTS AND DISCUSSION}

Whipping simply a mixture of epoxy resin/hardener did not result in a froth. However, it was possible to mechanically whip air into epoxy/hardener/silica formulations, resulting in a froth with a limited foam volume. Therefore, following earlier patented work ${ }^{4,22,31}$ disclosing foamed epoxy resins, we identified a suitable surfactant to aid foaming of our formulation. With surfactant liquid epoxy froths were successfully produced by mechanically beating air into a liquid epoxy formulation. Friberg ${ }^{16}$ in his review stated that the stability of nonaqueous froths depends not on the reduction of the gas/liquid interface tension but on the rheology of the liquid films. Therefore, surfactants do not stabilize nonaqueous froths by reducing the surface tension of the liquid resin/gas interface. In some cases, surfactants do form crystals and stabilize nonaqueous froths; ${ }^{32}$ however, we did not observe the formation of a crystalline phase in the liquid resin. Our hypothesis is that the surfactant (Pluronic L-81) phase separated from the epoxy system driven by small surface tension differences between the epoxy resin/hardener and the surfactant. During whipping of the epoxy formulations, the 
rheology of the heterogeneous liquid films improved the stability of the froths. The liquid froths were stable at room temperature; after storing the epoxy froths for 1 day at room temperature, they solidified into solid epoxy foams. These epoxy foams had a semiopen porous structure with spherical pores, which were templated by the air bubbles in the froths; some pores were connected by pore throats (Figure 1e). However, once the as-prepared liquid froths were placed into an oven at $60^{\circ} \mathrm{C}$, in an attempt to accelerate the curing of the froths, the liquid froths collapsed rapidly, resulting after curing in a nonporous epoxy block (Figure 1f). The elevated temperature resulted in a decrease of the viscosity of the liquid resin phase of the froth, which accelerated the drainage of the liquid from the films separating the air bubbles, resulting in coalescence of air bubbles.

To accelerate the production of epoxy foams by curing liquid froths at an elevated temperature, the viscosity of the liquid phase in the froth had to be increased to slow the drainage from the liquid froth at elevated curing temperatures. Therefore, silica particles were added into the epoxy resin/ hardener/surfactant mixture. The viscosity of the mixtures containing increasing silica loadings was measured. The pure liquid phase containing no and 0.2 wt $\%$ silica particles exhibited slight shear thinning; the viscosity decreased with increasing shear rate from 0.01 to $100 \mathrm{~s}^{-1}$, while the resin phase containing 0.5 to $10 \mathrm{wt} \%$ silica particles exhibited a more significant shear thinning behavior. Furthermore, the zero-shear viscosity of the mixtures increased with increasing silica loadings (Figure 2). The increased zero-shear viscosity of

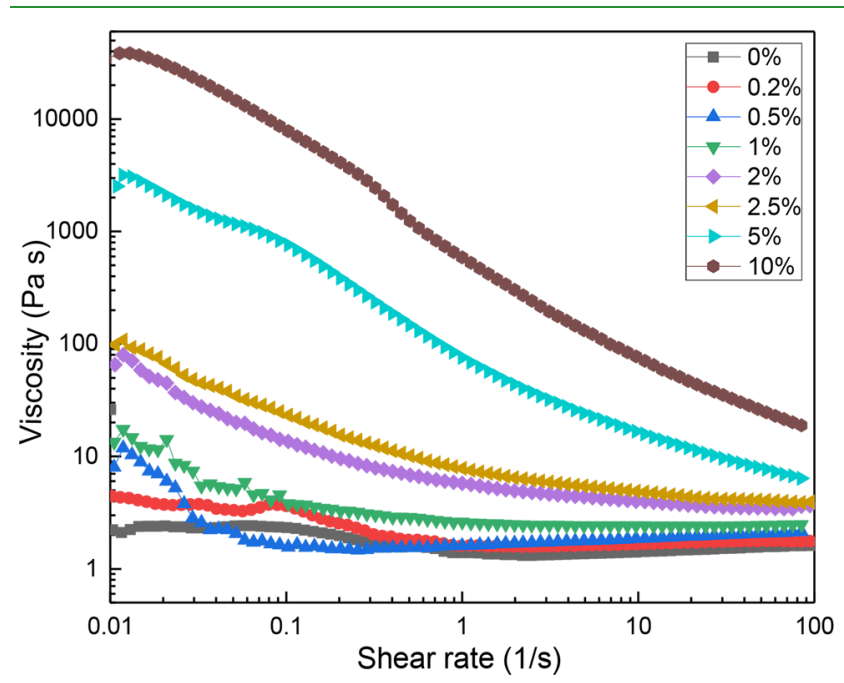

Figure 2. Viscosity of liquid resin phase consisting of epoxy, hardener, and surfactant with increasing silica particle loading as a function of shear rate.

the liquid phase with increasing silica particle loading is expected to favor the formation of stable froths, especially at elevated temperatures.

Epoxy foams were successfully produced by curing the liquid epoxy froths containing silica particles at $60^{\circ} \mathrm{C}$, during which the silica containing froths were all stable, i.e. the froth volume did not decrease. The epoxy froth containing $0.2 \mathrm{wt} \%$ silica particles was surprisingly stable during curing at $60{ }^{\circ} \mathrm{C}$ even though the zero-shear viscosity of the liquid resin phase with such low amount of silica was only $4 \mathrm{~Pa} \cdot \mathrm{s}$ as compared to $2 \mathrm{~Pa}$. $s$ for the pure resin without silica particles. A reduction of the percolation threshold of fillers in polymer foams as compared to bulk polymer has been reported; ${ }^{33,34}$ this has been explained by fillers being concentrated in the plateau regions in the liquid phase due to the relocation of the fillers during the frothing process. Therefore, regardless of the rheological behavior of the bulk liquid, the presence of silica particles in the plateau regions could arrest liquid film drainage and stabilize air bubbles against coalescence. ${ }^{35}$ The curing behavior of the epoxy froths was investigated by holding the liquid formulations at $60{ }^{\circ} \mathrm{C}$ for $3 \mathrm{~h}$ in a DSC. The epoxy foams were fully cured in $90 \mathrm{~min}$ (a detailed discussion can be found in the Supporting Information, Figure S2) irrespectively of silica particle loading. The skeletal and foam density of the epoxy foams (Figure 3a) containing 0.2 wt \% silica was 1.18
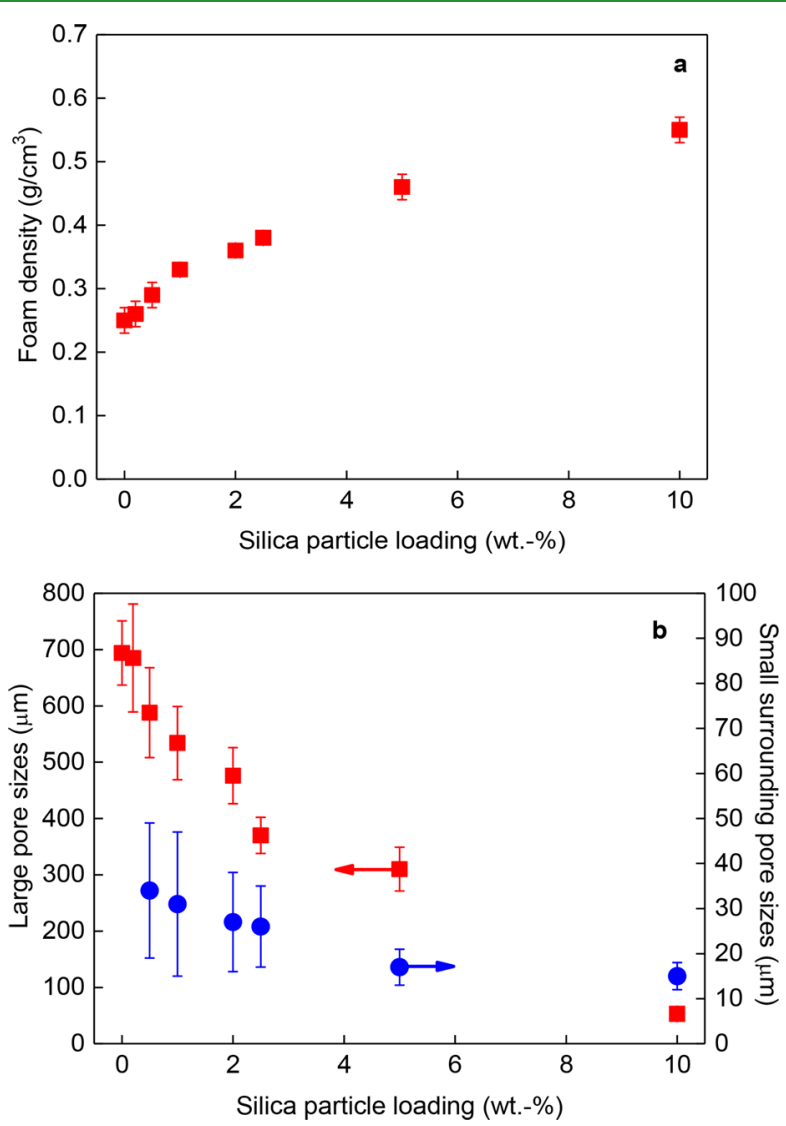

Figure 3. Foam density (a) and average pore size of large and small pores (b) of solid epoxy foams as a function of silica particle loading.

and $0.25 \mathrm{~g} / \mathrm{cm}^{3}$, respectively, resulting in a porosity of $79 \%$ (the physical, morphological, and mechanical properties of all epoxy foams are summarized in the Supporting Information, Table S1). Epoxy foams with silica particles possessed a closedcell structure (Figure 4). This can be explained by the presence of the silica particles, which retarded liquid film drainage in the epoxy froths during curing. As a result, the liquid films separating the air bubbles were not thin enough to allow pore throats to form during curing. Epoxy foams containing $0.2 \mathrm{wt}$ $\%$ silica particles had an average pore size of about $700 \mu \mathrm{m}$ : hardly any smaller pores with a diameter of about $100 \mu \mathrm{m}$ existed in the pore walls or plateau regions. With increasing silica loadings, the skeletal density of the epoxy foams was identical within error, which was $1.18 \pm 0.02 \mathrm{~g} / \mathrm{cm}^{3}$. However, the foam densities of the epoxy foams increased to about 0.55 

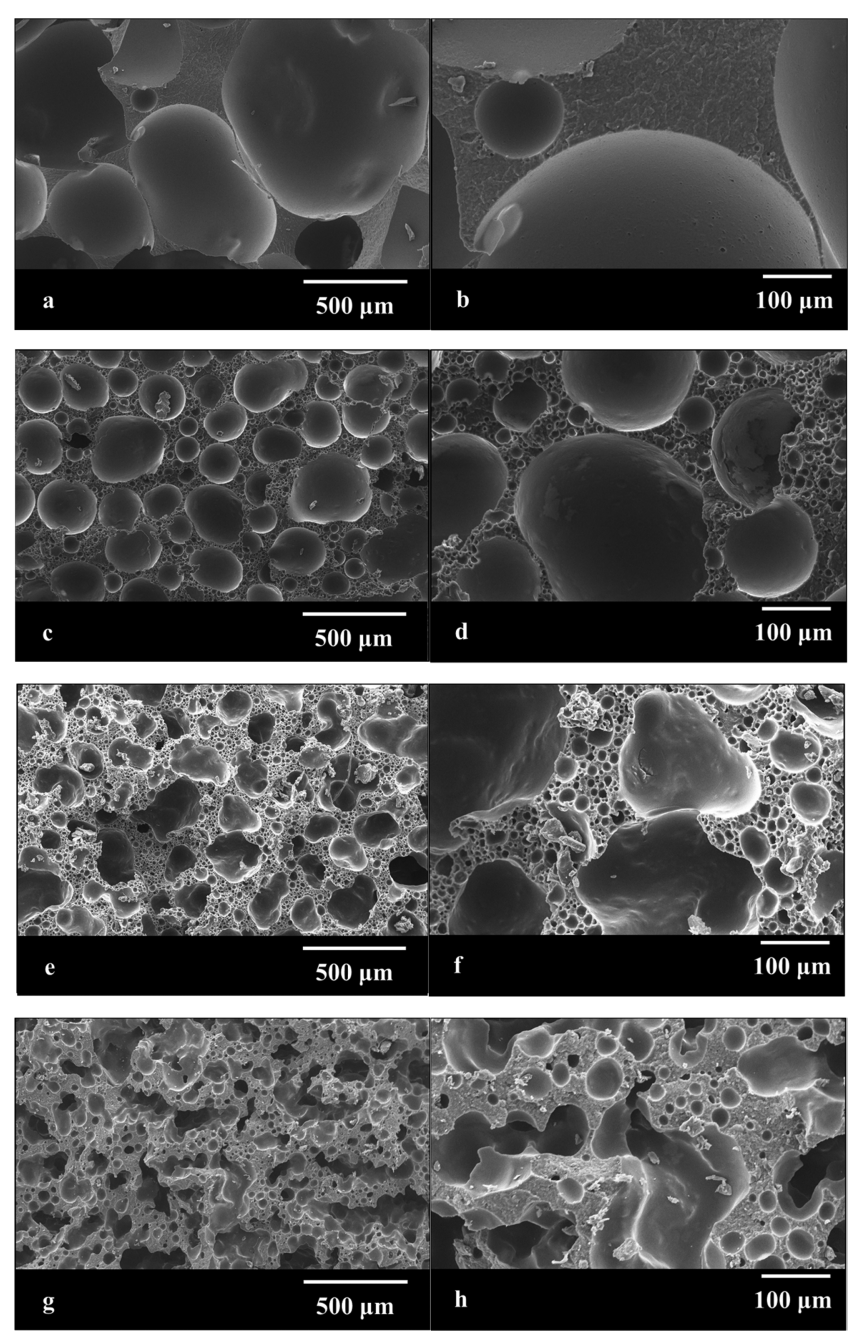

Figure 4. Characteristic SEM images of macroporous epoxy foams containing increasing amounts of silica particles: 0.2 (a, b), 2.5 (c, d), $5(\mathrm{e}, \mathrm{f})$, and $10 \%(\mathrm{~g}, \mathrm{~h})$ silica particles. With increasing silica particle loading, the morphology of the epoxy foams changed from a semiopen porous structure to a closed cell but hierarchical pore structure to a hierarchical pore structure with irregular pores.

$\mathrm{g} / \mathrm{cm}^{3}$ (Figure $3 \mathrm{a}$ ), leading to a decrease of the porosity from 79 to $54 \%$. Because all liquid froths in this group were produced with identical energy input (identical mixer and mixing tool, whipping time, and initial liquid phase volume), the liquid phase containing more silica particles, thus having a higher viscosity, was more difficult to be mechanically whipped, resulting in the froths with smaller froth volumes and thus lower air content. Moreover, the silica concentrations in the froths also affected the pore structure of the produced solid epoxy foams; the pore size distribution changed from a monomodal pore size distribution (epoxy foams containing no silica particles but cured at room temperature and $0.2 \mathrm{wt} \%$ silica particles, Figure 1A and Figures $4 \mathrm{a}$ and $\mathrm{b}$ ) to foams with a hierarchical pore structure, characterized by large pores with average diameters of hundreds of micrometers being surrounded by many smaller pores having an average pore diameter approximately one order of magnitude smaller (Figure $3 \mathrm{~b}$ and Figures $4 \mathrm{c}-\mathrm{h}$ show representative SEM images). Silica particles could function as nucleating agents to help regulate and stabilize gas bubbles during foaming polymers: ${ }^{4,90}$ such nucleation from silica particles must be in a foaming process, which starts from small gas bubbles (usually caused by phase separation of blowing agents) and bubble growth. However, in our case, the air bubbles were introduced by mechanical whipping; the air was entrained through the spout, and bubble break up occurred only later by shear. Therefore, in our case, the function of the silica particles was not to aid nucleation. Instead, the silica particles most likely formed a network or packed in the liquid films in the epoxy froths; the network or packed silica particles hindered the small air bubbles to coalesce, therefore stabilizing the froths with small bubbles in the liquid films. The curing of such froths therefore resulted in a hierarchical pore architecture containing both large and small pores. The epoxy foams produced by curing froths containing 5 and $10 \mathrm{wt} \%$ silica particles contained nonspherical pores (Figures $4 \mathrm{e}-\mathrm{h}$ ). Liquid films containing a high silica loading thus having an increased rigidity did not permit the bubbles, after being deformed during whipping, to relax into their equilibrium spherical shape, ${ }^{14}$ therefore resulting after curing in epoxy foams with irregular pores, e.g. channel-like or elliptical pores. We determined the size of the constrictions in these channel-like pores separating them in to smaller joined pores; the pore sizes for each of the individual pores was determined. Once the large pores had elliptical shapes, the average size of these pores was determined by measuring and averaging the long and short axis of the ellipse. Both the large and small pore sizes of the epoxy foam decreased with increasing silica particle loading (Figure $3 b)$, as the silica particles hindered the drainage from the liquid film and bubble coalescence in the initial epoxy froths.

Solid epoxy foams were rigid but not brittle, characterized by compressive stress-strain curves without failure up to strains of $30 \%$ (Figure 5a); the specimens buckled but exhibited no visible cracks during mechanical testing. As expected, the elastic moduli and crush strengths of the epoxy foams depended on the foam density; epoxy foams with higher foam densities had higher elastic moduli and crush strengths. To compare foams with different porosities and investigate the effect of the silica particles on the mechanical properties of the epoxy foams, the elastic moduli and crush strengths of the epoxy foams were normalized with respect to their foam density. The epoxy foams without silica particles had a specific elastic modulus of $348 \pm 32 \mathrm{MPa} /\left(\mathrm{g} / \mathrm{cm}^{3}\right)$ and a specific crush strength of $16 \pm 2 \mathrm{MPa} /\left(\mathrm{g} / \mathrm{cm}^{3}\right)$. With increasing the silica particle loading from 0.2 to $2.5 \mathrm{wt} \%$, the specific stiffness and crush strengths of the epoxy foams increased from $420 \mathrm{MPa} /$ $\left(\mathrm{g} / \mathrm{cm}^{3}\right)$ to $520 \mathrm{MPa} /\left(\mathrm{g} / \mathrm{cm}^{3}\right.$ ) (Figure $5 \mathrm{~b}$ ). Despite the incorporation of silica particles into pore walls of the epoxy foams, the reinforcing efficiency of silica particles at such low concentrations is low as predicted by the Guth-Gold relation. ${ }^{36}$ The glass transition temperature $T_{\mathrm{g}}$, determined by DMTA, of all epoxy foams was about $88^{\circ} \mathrm{C}$, indicating that the silica particles did not chemically interact with the epoxy matrix. The incorporation of silica particles, however, did affect the pore morphology and structure of the epoxy foams, which also affects the mechanical properties. For instance, Wong et al. ${ }^{37}$ reported that cross-linked polystyrene foams with a hierarchical pore structure produced by emulsion templating have a higher stiffness as compared to foams with a monomodal pore size distribution. Therefore, the increase of the specific elastic moduli and crush strengths could also be due to the change of the pore morphology of the epoxy foams from a single modal pore size distribution to a hierarchical pore structure. Increasing the silica particle loading to 5 and $10 \mathrm{wt} \%$ 

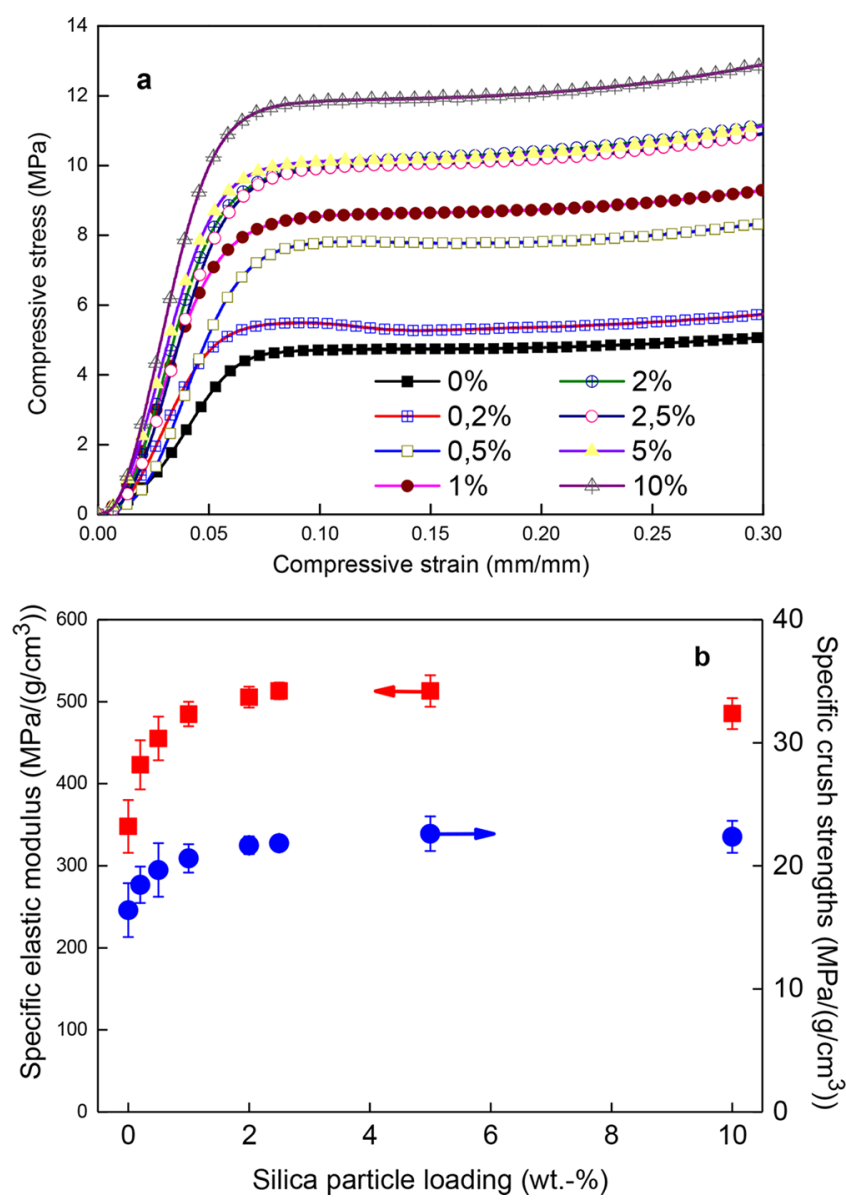

Figure 5. Stress-strain curves of epoxy foams (a) and specific elastic moduli and crush strengths of epoxy foams as a function of silica particle loading (b).

did not further increase the specific elastic moduli and crush strengths as compared to the epoxy foams containing smaller amounts of silica particles. However, the mechanical properties of the epoxy foams containing 5 and $10 \mathrm{wt} \%$ silica particles could be affected because those foams contained nonspherical pores; ${ }^{14,23}$ the pore walls of irregular shaped pores buckle much easier in compression as compared to the pore walls of spherical pores.

To investigate the introduction of air bubbles into the liquid phase, epoxy froths were produced using identical formulations (all with $2.5 \mathrm{wt} \%$ silica particles) but with increasing whipping times (and thus energy input) from 2 to $24 \mathrm{~min}$. The epoxy foams produced by curing froths whipped for 2 min possessed hierarchical porous structures with larger pores of an average size of $440 \mu \mathrm{m}$ and smaller pores with sizes of about $30 \mu \mathrm{m}$, while the epoxy foams obtained by curing 6 and $12 \mathrm{~min}$ whipped froths had smaller average pore sizes (Figure 6b). This finding supports our hypothesis that the air bubbles initially whipped into the liquid phase were large and that these larger air bubbles initially introduced into the template were broken up into smaller ones. Increasing the whipping time (from 2 to $12 \mathrm{~min}$ ) of the froths resulted in epoxy foams with a lower density. This was consistent with our observation that the volume of the froths increased with increasing whipping time from 2 to $12 \mathrm{~min}$, evidencing that an increasing amount of air was continuously entrapped into the liquid froths. However, when the froth was whipped for $24 \mathrm{~min}$, the froth volume
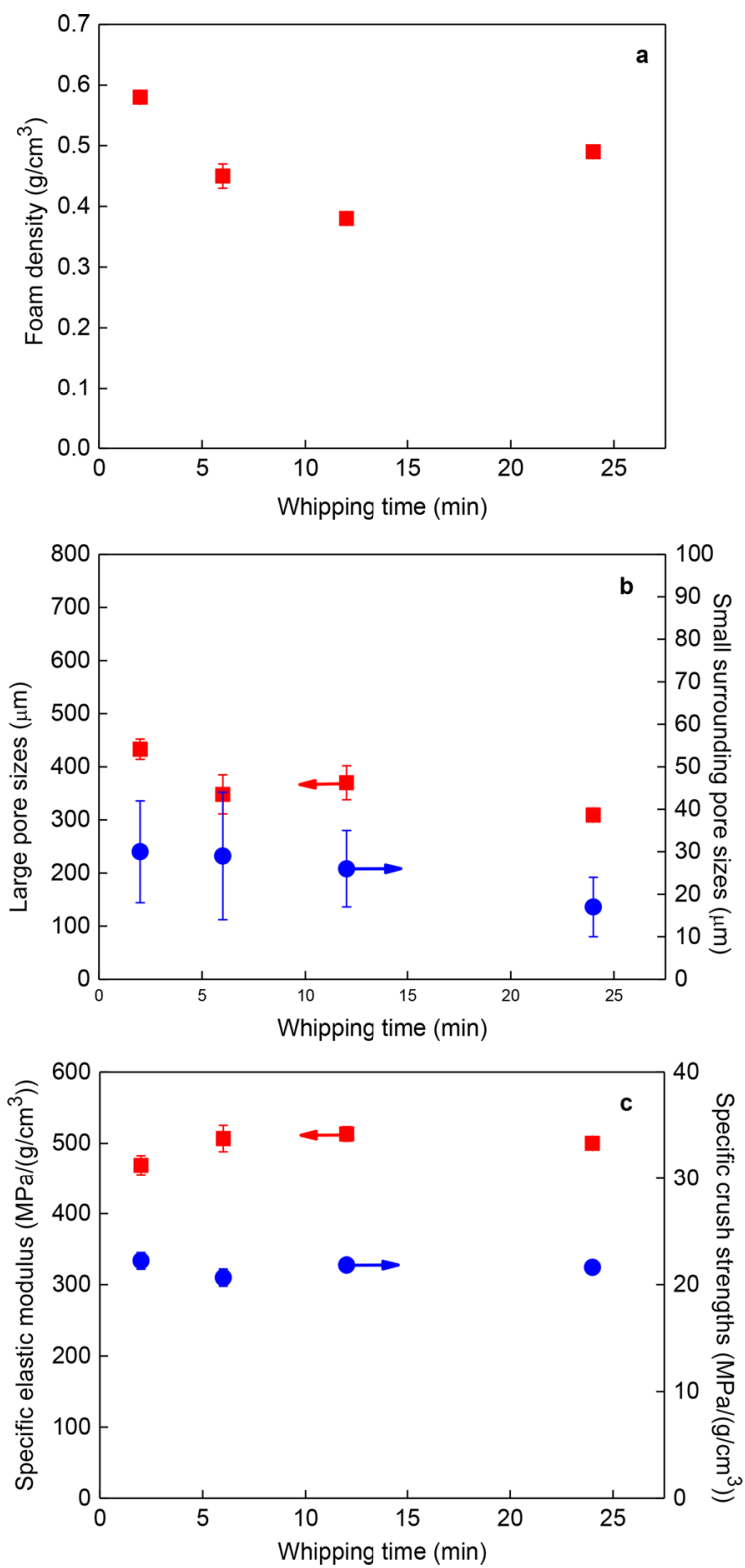

Figure 6. Foam density (a), average pore size (b), and specific elastic moduli and crush strengths $(c)$ of the epoxy foams as a function of whipping time used to produce the epoxy froths.

decreased again. After curing this template, the resulting epoxy foam had a higher density than the foams synthesized by curing froths produced with shorter whipping times (Figure $6 a)$. This indicated that "overwhipping" occurred between 12 to 24 min. "Overwhipping" is a well-known phenomenon when preparing whipped cream and is studied by food scientists. ${ }^{38}$ In our case, the reason for overwhipping could be the onset of the reaction between epoxy and hardener, resulting in an increase of the viscosity of the liquid froth phase or phase separation of the surfactant, which reduces the capability of the liquid phase to entrap more air, thus leading to a reduced froth volume. The average pore size of the large pores in epoxy foams produced by curing the overwhipped froths was further reduced to 309 $\mu \mathrm{m}$ as compared to the epoxy foams prepared from froths whipped for 2, 6, and $12 \mathrm{~min}$ (Figure 6b). This indicated that although air is gradually removed from the froths during overwhipping, larger air bubbles were still being broken. The 
epoxy foams produced from 2, 6, 12, and $24 \mathrm{~min}$ froths possessed hierarchal pore structures (Figure S4); they also exhibited similar specific elastic moduli and crush strengths because they had the same composition (Figure 6c).

The effect of curing temperature on the properties of the epoxy foams was investigated by curing epoxy froths of identical formulation and whipping time at 60,80 , and $100{ }^{\circ} \mathrm{C}$, respectively. Increasing the curing temperature from 60 to 80 and $100{ }^{\circ} \mathrm{C}$ resulted in epoxy foams with lower foam densities (Figure 7a). The increased curing temperature caused larger average pore sizes by thermal expansion of air bubbles before complete solidification of the liquid phase in the epoxy froths (Figure $7 \mathrm{~b}){ }^{24}$ The specific elastic moduli and the crush strengths of the epoxy foams produced by curing the liquid froths at 80 and $100{ }^{\circ} \mathrm{C}$ were slightly lower than those of the
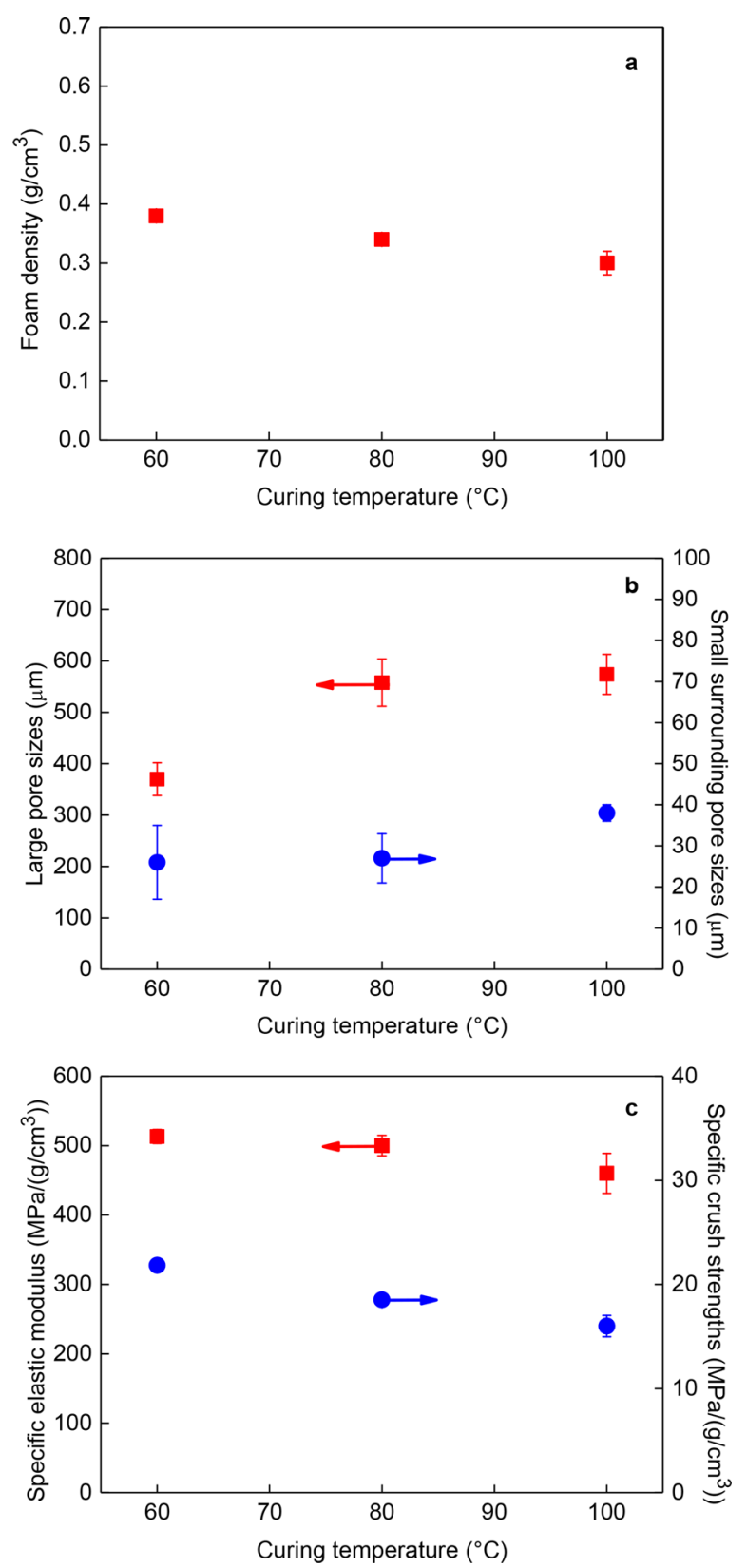

Figure 7. Foam density (a), average pore size (b), and specific elastic moduli and crush strengths (c) of the epoxy foams as a function of curing temperature of the epoxy froths. epoxy foam cured at $60{ }^{\circ} \mathrm{C}$ (Figure $7 \mathrm{c}$ ). The thermal expansion of the air bubbles in the froths caused the liquid films to stretch during air bubble growth, which resulted after curing in epoxy foams with thinner polymer walls and thus lower resistance to buckling in compression.

To compare the mechanical properties of the epoxy foams produced by us using the air templating method with the reported ones, the elastic moduli and crush strengths of the epoxy foams as a function of their foam density are plotted in Figure $8 \mathrm{a}$. The curves were fitted using the power law: ${ }^{2}$

$$
\begin{aligned}
& E=a \rho_{\mathrm{f}}{ }^{m} \\
& \sigma=b \rho_{\mathrm{f}}{ }^{n}
\end{aligned}
$$

where $E$ is the elastic moduli, $\sigma$ the crush strengths of the epoxy foams, and $a$ and $b$ material related constants, while $m$ and $n$ are structure related constants. The elastic moduli and crush strengths of the epoxy foams as a function of their density fit well to the power-law equation; $a$ and $b$ had values of 513 and 27, respectively, and $m$ and $n$ had values of 1.03 and 1.30 , respectively. Ashby ${ }^{39}$ reported that the failure of a porous material is due to stretching ( $m=1$ and $n=1)$ or bending ( $m$ $=2$ and $n=1.5$ ) of the pore struts or walls: in most cases foams exhibit a bending-dominated failure. However, our epoxy foams had lower $m$ and $n$ values, indicating more stretching of the pore walls prior to failure, as compared to previously reported epoxy foams. ${ }^{2,6,9}$ In Ashby's model, the force exerted on a strut of a nonrigid porous structure results in bending of strut and causes the deformation of the pore. In our epoxy foams, a majority of the large pore walls indeed underwent bending. Nevertheless, due to the hierarchical pore structure of our epoxy foams, the bending of the large pore wall must cause the deformation of each individual small pore therein. At this secondary scale, the smaller pores are considered as rigid structure and, therefore, the bending of the large pore walls was transferred to stretching of the small pores, resulting in an apparent stretching-dominated failure behavior of our epoxy foams.

The elastic moduli (Figure 8a) and crush strengths (Figure $8 b)$ of our epoxy foams are in line with other epoxy foams reported in the literature; $;^{2,6,9,40}$ the difference in the absolute values of the stiffness and strengths is due to the different epoxy resin/hardener formulations that have been used to prepare those samples. However, the stiffness and strengths of our epoxy foam composites did not decrease with foam density as steeply as for other reported epoxy foams: this indicates that the hierarchical pore structure is beneficial for the mechanical properties of low density epoxy foams (e.g., $<0.25 \mathrm{~g} / \mathrm{cm}^{3}$ ) (Figures $8 \mathrm{~b}$ and $\mathrm{c}$ ).

The specific elastic moduli and crush strengths were not affected by the average pore size of the large pores when the pore sizes increased from 50 to $450 \mu \mathrm{m}$. A further increase of the average pore size above $600 \mu \mathrm{m}$ resulted in a slight decrease of the elastic moduli and crush strengths. At normalized foam density, the presence of larger pores in epoxy foams indicates thinner pore walls, which have lower resistance to buckling during compression, resulting in reduced elastic moduli and crush strengths.

The thermal stability characterized by thermogravimetric analysis of the foamed epoxy composites characterized in air and nitrogen showed that the epoxy foams were stable without any significant weight loss up to at least $200{ }^{\circ} \mathrm{C}$ in air. The experimental and results can be found in the Figure S5. 


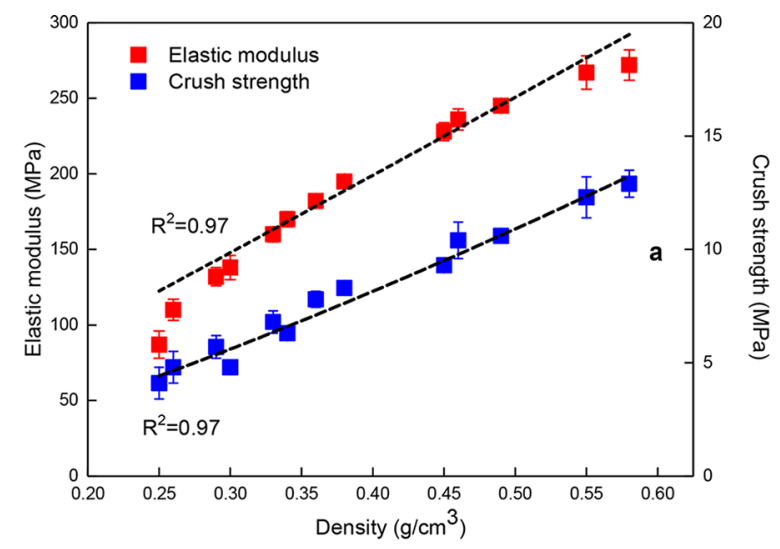

\section{CONCLUSIONS}

Epoxy foams were successfully produced by mechanically whipping air into an epoxy resin, hardener, surfactant, and silica particle mixture, resulting in a stable liquid froths, which could be subsequently cured into solid epoxy foams. Increasing silica particle loadings increased the stability of the froths by increasing the viscosity of the liquid phase of the froths, enabling the curing of the epoxy at elevated temperatures. Epoxy foams containing silica particles had a hierarchical macropore structure where the large pores were surrounded by smaller pores. Increasing the silica particle loading in the epoxy froths resulted in an increasing foam density and a decrease of the average (large and small) pore sizes in the epoxy foams. However, when the silica loading exceeded 5 wt \%, air bubbles introduced into the epoxy froths could not assume their equilibrium spherical shape after whipping stopped, leading to epoxy foams with nonspherical pores. The epoxy foams containing silica particles possessed specific elastic moduli and crush strengths higher than those of the epoxy foam with a monomodal pore size distribution.

\section{ASSOCIATED CONTENT}

\section{S Supporting Information}

The Supporting Information is available free of charge on the ACS Publications website at DOI: 10.1021/acsapm.8b00084.

Dimensions of the dough kneading head, heat flow of epoxy froths during curing, glass transition temperature of epoxy foams, summary of the properties of the epoxy foams, morphology of epoxy foam produced from froths produced from different whipping time, and thermal degradation behavior of epoxy foams (PDF)

\section{AUTHOR INFORMATION}

\section{Corresponding Authors}

*E-mail: qixiang.jiang@univie.ac.at.

*E-mail: alexander.bismarck@univie.ac.at.

ORCID $\odot$

Qixiang Jiang: 0000-0002-4315-2229

Alexander Bismarck: 0000-0002-7458-1587

\section{Notes}

The authors declare no competing financial interest.

\section{ACKNOWLEDGMENTS}

The authors acknowledge the financial support of JSP (https://www.jsp.com), which enabled this work. The authors also acknowledge the financial support from the HIPERM project (Grant I 1800 Internationale Projekte) provided by Austrian Science Fund (FWF).

\section{REFERENCES}

(1) Alonso, M. V.; Auad, M. L.; Nutt, S. R. Modeling the compressive properties of glass fiber reinforced epoxy foam using the analysis of variance approach. Compos. Sci. Technol. 2006, 66, 21262134.

(2) Wang, L.; Yang, X.; Zhang, J.; Zhang, C.; He, L. The compressive properties of expandable microspheres/epoxy foams. Composites, Part B 2014, 56, 724-732.

(3) Gupta, N.; Maharsia, R. Enhancement of Energy Absorption in Syntactic Foams by Nanoclay Incorporation for Sandwich Core Applications. Appl. Compos. Mater. 2005, 12, 247-261.

(4) Russick, E. M.; Rand, P. B. Epoxy foams using multiple resins and curing agents. US6110982A, 2000. 
(5) Alonso, M. V.; Auad, M. L.; Nutt, S. Short-fiber-reinforced epoxy foams. Composites, Part A 2006, 37, 1952-1960.

(6) Stefani, P. M.; Barchi, A. T.; Sabugal, J.; Vazquez, A. Characterization of epoxy foams. J. Appl. Polym. Sci. 2003, 90, 2992-2996.

(7) Foaming epoxy systems. http://www.sicomin.com/products/ epoxy-systems/foaming (accessed January 30, 2018).

(8) Allameh-Haery, H.; Kisi, E.; Fiedler, T. Novel cellular perliteepoxy foams: Effect of density on mechanical properties. J. Cell. Plast. 2017, 53, 425-442.

(9) Xu, Y.; Li, Y.; Bao, J.; Zhou, T.; Zhang, A. Rigid thermosetting epoxy/multi-walled carbon nanotube foams with enhanced conductivity originated from a flow-induced concentration effect. RSC Adv. 2016, 6, 37710-37720.

(10) Chen, K.; Tian, C.; Lu, A.; Zhou, Q.; Jia, X.; Wang, J. Effect of $\mathrm{SiO} 2$ on rheology, morphology, thermal, and mechanical properties of high thermal stable epoxy foam. J. Appl. Polym. Sci. 2014, 131, 40068.

(11) Wang, J.; Zhang, C.; Du, Z.; Xiang, A.; Li, H. Formation of porous epoxy monolith via concentrated emulsion polymerization. $J$. Colloid Interface Sci. 2008, 325, 453-458.

(12) Wang, J.; Du, Z.; Li, H.; Xiang, A.; Zhang, C. Interconnected porous epoxy monoliths prepared by concentrated emulsion templating. J. Colloid Interface Sci. 2009, 338, 145-150.

(13) Barron, B.; Dunlap, J. Air frothed polyurethane foams. US3821130A, 1974.

(14) Lee, K. Y.; Wong, L. L. C.; Blaker, J. J.; Hodgkinson, J. M.; Bismarck, A. Bio-based macroporous polymer nanocomposites made by mechanical frothing of acrylated epoxidised soybean oil. Green Chem. 2011, 13, 3117-3123.

(15) Szczurek, A.; Fierro, V.; Pizzi, A.; Celzard, A. Mayonnaise, whipped cream and meringue, a new carbon cuisine. Carbon 2013, 58, $245-248$.

(16) Friberg, S. E. Foams from non-aqueous systems. Curr. Opin. Colloid Interface Sci. 2010, 15, 359-364.

(17) Wong, J. C. H.; Tervoort, E.; Busato, S.; Gonzenbach, U. T.; Studart, A. R.; Ermanni, P.; Gauckler, L. J. Macroporous polymers from particle-stabilized foams. J. Mater. Chem. 2009, 19, 5129-5133.

(18) Studart, A. R.; Gonzenbach, U. T.; Tervoort, E.; Gauckler, L. J. Processing Routes to Macroporous Ceramics: A Review. J. Am. Ceram. Soc. 2006, 89, 1771-1789.

(19) Pan, Y.; Wang, W.; Peng, C.; Shi, K.; Luo, Y.; Ji, X. Novel hydrophobic polyvinyl alcohol-formaldehyde foams for organic solvents absorption and effective separation. RSC Adv. 2014, 4, 660-669.

(20) Jalalian, M.; Jiang, Q.; Birot, M.; Deleuze, H.; Woodward, R. T.; Bismarck, A. Frothed black liquor as a renewable cost effective precursor to low-density lignin and carbon foams. React. Funct. Polym. 2018, 132, 145-151.

(21) Schüler, F.; Schamel, D.; Salonen, A.; Drenckhan, W.; Gilchrist, M. D.; Stubenrauch, C. Synthesis of Macroporous Polystyrene by the Polymerization of Foamed Emulsions. Angew. Chem., Int. Ed. 2012, 51, 2213-2217.

(22) Simpson, S. S.; Yeznach, A.; Barton, C. L. Epoxy foam. US4546118, 1985.

(23) Lau, T. H. M.; Wong, L. L. C.; Lee, K. Y.; Bismarck, A. Tailored for simplicity: creating high porosity, high performance bio-based macroporous polymers from foam templates. Green Chem. 2014, 16, 1931-1940.

(24) Song, W.; Barber, K.; Lee, K. Y. Heat-induced bubble expansion as a route to increase the porosity of foam-templated bio-based macroporous polymers. Polymer 2017, 118, 97-106.

(25) Stefani, P. M.; Cyras, V.; Tejeira Barchi, A.; Vazquez, A. Mechanical properties and thermal stability of rice husk ash filled epoxy foams. J. Appl. Polym. Sci. 2006, 99, 2957-2965.

(26) Mahrholz, T.; Stängle, J.; Sinapius, M. Quantitation of the reinforcement effect of silica nanoparticles in epoxy resins used in liquid composite moulding processes. Composites, Part A 2009, 40, $235-243$.
(27) Wu, R.; Menner, A.; Bismarck, A. Tough interconnected polymerized medium and high internal phase emulsions reinforced by silica particles. J. Polym. Sci., Part A: Polym. Chem. 2010, 48, 19791989.

(28) Ikem, V. O.; Menner, A.; Bismarck, A. Tailoring the mechanical performance of highly permeable macroporous polymers synthesized via Pickering emulsion templating. Soft Matter 2011, 7, 6571-6577.

(29) Khankrua, R.; Pivsa-Art, S.; Hiroyuki, H.; Suttiruengwong, S. Thermal and Mechanical Properties of Biodegradable Polyester/Silica Nanocomposites. Energy Procedia 2013, 34, 705-713.

(30) Skelhon, T. S.; Grossiord, N.; Morgan, A. R.; Bon, S. A. Quiescent water-in-oil Pickering emulsions as a route toward healthier fruit juice infused chocolate confectionary. J. Mater. Chem. 2012, 22, 19289-19295.

(31) Gormley, W. T.; Gillespie, G. J. Thermoset epoxy foam compositions and a method of preparing the same. US4090986, 1978.

(32) Shrestha, L. K.; Aramaki, K.; Kato, H.; Takase, Y.; Kunieda, H. Foaming Properties of Monoglycerol Fatty Acid Esters in Nonpolar Oil Systems. Langmuir 2006, 22, 8337-8345.

(33) Ameli, A.; Jung, P. U.; Park, C. B. Electrical properties and electromagnetic interference shielding effectiveness of polypropylene/ carbon fiber composite foams. Carbon 2013, 60, 379-391.

(34) Li, J.; Zhang, G.; Ma, Z.; Fan, X.; Fan, X.; Qin, J.; Shi, X. Morphologies and electromagnetic interference shielding performances of microcellular epoxy/multi-wall carbon nanotube nanocomposite foams. Compos. Sci. Technol. 2016, 129, 70-78.

(35) Rio, E.; Drenckhan, W.; Salonen, A.; Langevin, D. Unusually stable liquid foams. Adv. Colloid Interface Sci. 2014, 205, 74-86.

(36) Guth, E. On the hydrodynamical theory of the viscosity of suspensions. Phys. Rev. 1938, 53, 322-325.

(37) Wong, L. L. C.; Ikem, V. O.; Menner, A.; Bismarck, A. Macroporous Polymers with Hierarchical Pore Structure from Emulsion Templates Stabilised by Both Particles and Surfactants. Macromol. Rapid Commun. 2011, 32, 1563-1568.

(38) Smith, A. K.; Goff, H. D.; Kakuda, Y. Microstructure and rheological properties of whipped cream as affected by heat treatment and addition of stabilizer. Int. Dairy J. 2000, 10, 295-301.

(39) Ashby, M. F. The properties of foams and lattices. Philos. Trans. R. Soc., A 2006, 364, 15-30.

(40) Altuna, F. I.; Ruseckaite, R. A.; Stefani, P. M. Biobased Thermosetting Epoxy Foams: Mechanical and Thermal Characterization. ACS Sustainable Chem. Eng. 2015, 3, 1406-1411. 